\title{
Blended Lifelong Learning: A Practitioner's Approach
}

\section{Athanasios Apostolopoulos}

School Head, Professional High School Kalavryta, Greece

doi: 10.7358/ecps-2014-010-apos

athapos@gmail.com

\section{LA FORMAZIONE CONTINUA DEGLI ADULTI \\ IN MODALITÀ "BLENDED LEARNING»: \\ UN APPROCCIO SITUATO}

\begin{abstract}
This paper reports on the various theories of blended learning and student interaction with emphasis given to lifelong/adult learning. In our application, we assess the interaction elements established in Anderson and Miyazoe, and namely that teacher-student interaction takes precedent in skill-based training. Our empirical case study also largely corroborates most of the claims made by Knowles' andragogy concept. We demonstrate that technology itself can never be a substitute for sound teaching, but it can become a tremendous tool in designing and implementing a variety of previously unattainable strategies and courses within the existing natural constraints of online or blended learning. In addition, applications depend heavily not just on technical considerations and support, but on the contextsubject, the actors involved (tutors, students and support stuff) and the ability of all the parties involved to adapt in a timely fashion to unforeseen challenges in synchronicity. On the whole, it seems that by its very nature, blended learning is well suited to mature students since they are likely to be influenced by time and cost constraints while they have the personal motivation and experience necessary to be able to make constructive suggestions for improvements to a given course or curriculum.
\end{abstract}

Keywords: Adult learning, Andragogy, Blended learning, Interaction, Lifelong learning. 


\section{INTRODUCTION}

In the past 30 years there have been three major innovations in education, namely, the adoption of relentless testing, all too often standardized along national/international lines to enhance teacher accountability and uniformly measure student performance, the development of ranking systems for schools and universities which allow comparisons between institutions, and the realization of the potential of Information and Communication Technology (ICT) to facilitate the implementation of new theories as to how, why and when people learn (Zemsky et al., 2003). Obviously, the latter has received the most attention, not just because of the dotcom hype and the associated brouhaha, but, because it was the only one truly associated with progress in education. Testing predictably quantifies educational results, but it has also changed the nature of education - into teaching for the test. The development of ranking systems is nothing more than a straightforward application of Spence's signalling problem (Spence, 1973). It was envisaged that e-learning had the potential to shift education to the student centred approach by being design rich, able to deliver anywhere at any time, customizable to take full advantage of each students' personal learning style, while delivering, in some cases, certain economies of scale. As we shall see, the results were at best mixed, and when the dust settled, realism prevailed over unfounded optimism. Sorensen (2006) presents a very readable collection of what future trends e-learning was expected to herald at the time, and we can see - with or without the benefit of hindsight - just how over-optimistic or completely off the mark certain things really were.

The paper is organized as follows. Section 2 gives the definitions of e-learning, its characteristics and purposes expressed in a variety of settings, and uses an enhanced version of Rowley (1997) as an approach of which elements one should take into account when designing a viable e-course. Section 3 gives the natural advantages and disadvantages of distant communication, extending into e-learning and the challenges that have been encountered through excess optimism, the failure to understand the nature of virtual learning or simply by the nature of the shift itself to e-learning for a given organization. Section 4 briefly reviews the concept of andragogy devised by Knowles. Section 5 presents the findings of Anderson along with the contributions of Miyazoe, Rhode and Bernard on interaction and blended learning. Section 6 gives our own experience from the MSc in «Leadership and Management in Education", which is conducted in conjunction with "Roma Tre» University as a blended e-learning course aimed at professional teachers, while the final section is a conclusion. 


\section{BLENDED LEARNING}

E-learning is simply the use of ICT and other electronic media in education and other vocational training. On the other hand, blended learning - the combination of traditional face-to-face $(\mathrm{F} 2 \mathrm{~F})$ learning with e-learning - is slightly more ambiguous, mainly because of its greater scope (there are simply too many combinations). The narrowing and final pinning down of the term came with two seminal books on the subject by Bonk et al. (2006) and Garrison (2008). The former defines blended systems as ones that combine F2F instruction with computer mediated instruction, since they constitute two historically different systems of teaching and learning. Garrison, on the other hand, goes further into the context side of blended learning and examines its apparent opportunities and challenges:

Blended learning is the thoughtful fusion of face-to-face and online learning experiences. The basic principle is that face-to-face oral communication and online written communication are optimally integrated such that the strengths of each are blended into a unique learning experience congruent with the context and intended educational purpose. Although the concept of blended learning may be intuitively apparent and simple, the practical application is more complex.

A very good exposition of the evolution of the term and a useful heuristic diagram is given in Friesen (2012), who ends up with the following definition:

«Blended learning» designates the range of possibilities presented by combining Internet and digital media with established classroom forms that require the physical co-presence of teacher and students.

During the past fifteen years there have been numerous contributions on the subject of incorporating e-learning into existing educational structures (turning them into blended) or designing ones from scratch. These include Pritchard (2007) on constructivist pedagogic evolution by the gradual incorporation of digital technologies into classrooms, Littlejohn and Pegler (2007) on challenges and opportunities for new designs, Zellweger (2003, 2007 and $2007 \mathrm{~b}$ ) on strategic management for higher education which focuses on the internal structural and cultural conditions that must apply for a successfulsmooth transition to e-learning within Universities, and D'Angelo on designs of didactic methodologies and contents with emphasis on foreign languages. There have also been many contributions from national (e.g. InWEnt, 2006) and international (UNESCO, 2013; Euroleague, 2012) official organizations which often set (conflicting) goals and codes of practice. 
At the same time, there has been a lively debate on the successful implementation of e-learning strategies which revolves around the following themes (Zellweger, 2003; Guglielman, 2013):

- Accessibility, the latter puts forward a more complete definition including not just the technological component, but also the methodological-didactic one which includes pedagogical relationships and participative aspects for integration and inclusion, psychological components and cognition.

- Equity, in the sense of equal opportunities.

- Quality of education.

- The lag between reforms in the economic and educational sphere.

To these one could add the overall setting in the sense of the social, cultural and economic situation of the actors involved (students, teachers) and their surrounding environment.

If we examine the whole issue as a system and take a cue from Rowley, Lujan and Dolence (1997), the key strategic questions for education in general, shift from «Who will our students be? What should we teach? and How should we teach it?" to "Who is teaching what to whom, in what way and with which goal in mind». It is the objective (goal) and the natural limitations and/or possibilities (of the actors themselves and their setting) that will determine the process. In this light, blended learning just gives additional options on how to achieve the goal in question. Bates (1990), for instance, argued that interactivity should be the primary criteria for selecting media for educational delivery (the how). Hence, it becomes a tool that widens possibilities rather than an end in itself. The five aforementioned questions have actually been the subject of fierce debate among the various pedagogical schools of thought. Very briefly, it matters whether students are participating voluntarily, their ability, prior knowledge, their motivation, aspirations, personality etc. Similarly, teachers should be well versed in their subject, preferably experienced, with good interpersonal skills, be motivated, proactive etc. Furthermore, past experience and the established socio-cultural situation do matter, which is probably why so many are reporting disappointing results in fostering cooperation especially at advanced ages - if one is conditioned in a competitive environment, one will find it hard to operate in a collaborative setting.

In the next section we will examine the natural differences between F2F and ICT type of communication in order to determine the limitations and possibilities at hand, as well as the extent that the former can be mitigated by blended learning (and, hence, determine the mix of blending required). 


\section{F2F vs. ICT}

In the initial attempts at e-learning by various institutions, mainly universities, a number of myths were laid bare. There were four initial assumptions given in Zemsky and Massy (2003): firstly, if we build it, they will come; secondly, the students will take to e-learning like ducks to water; thirdly, e-learning will force a change in how we teach; lastly, an assumption related more to the potential for e-learning to build bridges across learning communities, electronically mediated learning would lead rapidly to the development of international networks linking both scholars and learners. Very briefly the students would "come» if and only if the new paradigm is clearly superior to the one it is replacing. The students are not blank pieces of paper: they have already had experience in getting educated in very different ways than the ones often imposed on them (the duck needs oxygen too!) and, as already mentioned, e-learning is a teaching tool not a method. What, in fact, it does change is the participants it attracts, and some things such as storage and lagged (asynchronous) communication become easier in every way. However, other aspects (often) present insurmountable challenges. What we have seen, though, is a growth in networks - albeit homogeneous in nature: scholars with scholars and learners with learners (the latter through social media no less!).

We will use Heller's analysis of F2F vs. Virtual Communication since it is concise and well documented.

Advantages of F2F include the transfer of tacit knowledge or knowledge gained through experience, the use of non-verbal cues and the ability to make timely adjustments, the ability to easily emphasize and or exchange personal information and to build trust.

The disadvantages of F2F include a manifestation of power differences inhibiting trust in heterogeneous groups, lower minority expression and higher costs.

Virtual communication, on the other hand, provides greater equality, gives access to the physically disadvantaged, reduces costs, allows communication across time zones and locations, enables access to experts, and so on.

Conversely, virtual communication is often beset with technical problems, often encounters synchronization issues, requires relevant training and familiarity with technology, deprives social presence and can often lead to interpersonal conflict. It often creates information overload and can lead to herd type behaviour through the emergence of group leaders in forums.

There are extra challenges when it comes to e-learning. As Dillon and Green (chapter 16 in Moore \& Anderson, 2003) correctly point out, e-learning is by definition/nature lonely, so it is extremely hard to foster teamwork 
or collaboration. The absence of physical group contact (see the advantages of $\mathrm{F} 2 \mathrm{~F}$ ) reduces group ties and motivation. Hence, it requires a lot more personal motivation by the student to obtain a satisfactory educational result. In general, and this applies to teachers and especially to students, different memories and varying motivations will manifest in different ways depending on the context and distance, whether physical or transactional (pedagogical gap). One solution is to individualize learning. The problem, as Greville Rumble (chapter 47) and Insung Jung (chapter 48) point out in the Handbook of distance education, is that this raises the cost dramatically (if you split a class of 28 students into four classes of 7 , you will need extra work hours per student regardless of the communication technique). In actual fact, the truth lies somewhere in the middle. It depends on how the «individualization» occurs. One good example is presented in Castello, Guglielman et al. (2013) in the context of complex learning. Of course, this does not mean that the adoption of e-learning means no financial problems. Financial restrictions due to educational policies or lack of funds, especially in a situation where one has to invest in technological infrastructure for a switch and/or enhancement of the e-learning component, can be particularly off-putting.

Further problems are encountered with the implementation of e-learning strategies when culture factors weigh in as is often the case in higher education. For example, Zellweger (2003 and 2007b) finds that staff (teaching and administrative personnel) consider many of the changes intrusive and either refrain from using the array of possibilities available or even undermine it altogether. This is not as surprising as it may seem. Universities are generally extremely conservative institutions (their structure has largely been unchanged since Medieval times) and there are bound to be turf wars, prestige issues (see the qualities of the educator in the previous section) or simply a failure by the teaching staff to appreciate the opportunities offered, due to a predetermined mindset about what constitutes teaching and learning.

In addition, there are pedagogical issues such as whether students have the technical skills to adopt e-learning, whether the teaching staff is indeed equipped to utilize the tools available, and the lack of expert knowledge in designing online courses from scratch or in adopting the right method for their specific needs.

Last, but not least, there are management and organizational issues involved in the shift to virtual teaching. As Zellweger points out: «[...] virtual learning means establishing a new mode of teaching and learning, creating a technical environment to support it, communicating perpetually about the project to change deeply rooted attitudes and, finally, working out a sustainable financial model» for the operation to be viable. 


\section{ANDRAgOGY}

The term «adragogy» coined by Malcolm Knowles comes from «andr(as)», which means man, and "agogi» (ago), which means leadldrive. It was coined in order to define adult education and, at the same time, to distinguish it from pedagogy (education for children). In The modern practice of adult education (1970), Knowles separated teaching for adults from teaching for children (pedagogy) by positing four assumptions/claims:

1. Adults move from dependency to self-directedness. The teacher is not the sole expert, the student is not an inexperienced child.

2. They draw upon their reservoir of experience for learning. The experiences of a lifetime of experience allow the adult learner to bring more to the table, and they ought to be celebrated and become part of the process.

3. They are ready to learn when they assume new roles; adults who choose to return to school later in life do so because they choose to. Adults tend to be more internally motivated and intentional.

4. They want to solve problems and apply new knowledge immediately. Problem-centred learning and practical assignments work well with this student group.

Thus, he argued that because of these differences, adults can employ resources simply not available to children. Hence, the teaching method should be shaped so as to create a climate conducive to learning that is ever mindful of the above traits of adult learners. Our assumption should be that the adult learner will actively participate in an informed and intentional way in their educational process.

According to Knowles, the role of the adragogic educator should be to:

a. Create a supportive, cooperative learning climate.

b. Involve the adult learners in the planning and amount of work in the course.

c. Take time to find out the adult learners' needs and interests.

d. Create learning objectives based on the adult learners' needs and interests.

e. Build courses around a sequenced set of problems, to achieve the aforesaid objectives.

f. Assess the quality of the learning experience through course evaluations and interviews with the adult students. 


\section{INTERACTION AND BLENDED LEARNING}

According to Anderson (2003a), an interaction consists of «reciprocal events that require at least two objects and two actions. Interactions occur when these objects and events mutually influence one another». In an educational setting there are both formal and informal interactions, and modes of interaction are formed by the interplay of students, teachers and content with themselves, and with each of the other elements. From these relationships the Interaction Equivalency Theorem (IET) was stated as follows:

Deep and meaningful formal learning is supported as long as one of the three forms of interaction (student-teacher; student-student; student-content) is at a high level. The other two may be offered at minimal levels, or even eliminated, without degrading the educational experience.

High levels of more than one of these three modes will likely provide a more satisfying educational experience, though these experiences may not be as cost or time effective as less interactive learning sequences.

There are three additional studies on Anderson's concept of interaction worth mentioning. Rhode adds the dimension of formal and informal interactions in the IET context, while Bernard et al investigated synchronous versus asynchronous learning. The third study by Miyazoe and Anderson and Miyazoe (2010) on how interaction works at different teaching settings (F2F, distant, blended) and for different materials, found that

the perceived priority order of interaction elements by the students clearly had certain patterns: the students place a higher value on the teacher element for the face-to-face mode and content for online courses; however, the preference is divided in all three elements for the blended learning form with increased online interaction among students. It also found that a skill-based course called for a high value on teacher elements, whereas the preference is divided with knowledge-based course. These suggest that the valued interaction elements differ in learning modes and content orientations. Varying the emphasis on the interaction elements in our course design depending on the contexts is therefore more efficient and, hence, is recommended.

\section{PRACTICAL APPLICATION}

Our collaboration with «Roma Tre» University for a blended MSc in «Leadership and Management in Education» started in 2006 with merely 4 students, and the number reached 54 in 2013/2014. The course consists of 
online instruction through lecture notes and other related bibliographical material combined with online seminars and a number of group trips on campus for onsite lectures, workshops and presentations. The vast majority of the coursework is done through essays. Essentially, studying from Greece in this setting entails that one masters the language as well as the course material with a minimal lag, while most of the work is done online (so one can think of it as double mixed learning).

The average age of the participants is about 45 years old, all coming from the education sector and all working while studying. As a group, they are highly motivated since they almost uniformly chose the course for career advancement; they are already trained and experienced, and have clear goals in mind as far as the course is concerned. A number of them (about 10\%) each year makes rather useful suggestions on possible improvements both on course content and on the methods employed; it is usually the first group to take up self-directness (we will risk a guess here, that this probably also reflects the real percentage of excellent teachers in Greek schools).

Our background was in teaching and the organization we set up had already had experience with computer science classes, from beginner to advanced level, in a variety of subjects. Hence, the transition with regard to technology and support for online course delivery was quite smooth. Experience since 2006 has shown that if one is to make a big leap, then, afterwards, incremental change is the way to go. We had to support our students on three fronts: software-technical aspects, language and course tutoring.

As regards software, we chose to work with Moodle, a program we had prior experience with programming (from the start we moved from version 1.6 to 2.5). Adjustment was difficult at the start, but we devoted a great deal of effort in the upgrades, introductory seminars, almost continual helpdesk support, indexing of materials and on making the interface more user-friendly. Surprisingly, age is not a factor when it comes to getting familiar with the software - probably because no one had any sort of exposure to Moodle beforehand.

Italian is a special language as far as Greeks are concerned. Firstly, it uses the Latin-based alphabet, which, even though different from the Greek one, is known to most Greeks since they are already familiar with English (from school, etc.). However, unlike English, Italian grammar and syntax is essentially a very simplified version of Greek. Hence, it is probably the easiest language for Greeks to learn and ideal for fast-paced learning. Initially, we let the students decide whether they should learn with our in-house team or not. The results, though, left much to be desired since learning was quite asymmetrical between students. The ones who chose to learn the language elsewhere turned out to be ill-prepared especially in terminology (the language might be easy enough, but teaching in this case was not tailored to student and/or content). 
So in 2010 we integrated the language and hired more staff for teaching and support (a serious advantage when starting from scratch is that one can actually mould the culture and structure of the organization as one goes along) so that students move in sync with the course development and according to their ability and prior knowledge. The results surpassed our expectations.

What came as a surprise, even to us, were the results and the student responses in the course itself, conducted from a distance through tutoring (forums, e-mails, webex). The first thing that became immediately evident was that the students showed incredible independent mindedness, but slower (and varied) self-directness when it came to the course content. Since they were already working in a school, they could easily identify which parts of theory were already applicable or not, and they constantly made interesting notes and comments on the applicability of the course content in the real world. In addition, we tailored their elective courses to the two other components of the program (technical and linguistic) so as to enhance the pace and quality of learning. This is one of the two ways to increase student-content interaction; the other comes through the mix of elective courses.

Consistent with the results mentioned above, our students placed most emphasis on tutors (it is a skills-based course) and then on content. We also found that typical issues which occur in school teaching, such as being proactive or preventing conflict before it escalates, also apply in online environments. The main differences are that the tutor has more time to react to potential trouble, but has a lot more difficulty - especially in the beginning - in spotting it (see section 3). Another responsibility, especially at the beginning of the course year, is to help the participants adapt. Due to age and past experience (or rather inexperience with online learning) we found that about $20 \%$ of the students need additional support for the first 2-3 months. For instance, the need to use the database available, the forum, e-mail etc. Finally, tutors have to constantly monitor the students and give encouragement when necessary (even people who are motivated have fluctuating moods), through dense communication and feedback exchange. The final point practically gives the economic limitations for the course itself. Even when the tutor him/herself gets accustomed to virtual teaching and manages to identify and solve problems in a timely fashion, the amount of time required per student means that one can handle about 20-30 students depending on experience and stamina. Part of the problem can be solved by upgrading the size and role of the support team and the aforementioned number can probably rise quite substantially.

One would expect moderately or high synchronicity in student learning, since they all come from the same sector and have the same time available for study (weekends, afternoons, school vacations etc.). However, with 
regard to synchronicity and especially to collaboration, the results are actually disappointing. Students prefer to work more with their tutors than with each other. In addition to the nature of the course, it is likely that the distance and their tight schedules (they mostly work while studying) does not give them the opportunity to work in forums etc. This may also be due to established attitudes, previous learning experiences or the inability to use these means effectively in the course context (it requires a lot of self study).

\section{CONCLUSION}

We saw that e-learning can offer tremendous opportunities especially at a time when funding is tight. It can provide an optimal mix of student interaction, but, as one would logically expect, the emphasis must first and foremost be given to context. The e-learning technique itself is a tool, not an end in itself. The content and method of teaching should respond in accordance with the teaching environment, so we see blended learning as the optimal mix for the future, barring natural constraints (for instance, you obviously cannot have an anatomy lab online ... yet), due to its great flexibility. In order to make use of this flexibility, the different parts of the organization must be in constant communication with one another, often at an additional cost. On the other hand, the medium of teaching will not produce magic results, such as collaboration, on its own. People who have already learnt how to work on their own, in a setting made for individuals (distant learning), with material made for physical classes, will not magically start collaborating. Perhaps more emphasis should be placed on team assignments, on receiving student feedback, and on how to nurture such behaviour if it is actually required.

\section{REFERENCES}

Anderson, T. (2003a). Getting the mix right again: An updated and theoretical rationale for interaction. International Review of Research in Open and Distance Learning, 4(2). Retrieved from: http://www.irrodl.org/index.php/ irrodl/article/view/149/230.

Anderson, T. (2003b). Modes of interaction in distance education: Recent developments and research questions. In D. M. Moore (Ed.), Handbook of distance education (pp. 129-144). Mahwah, NJ: Lawrence Erlbaum Associates Publishers. 
Anderson, T., \& Miyazoe, T. (2010). The interaction equivalency theorem. Journal of Interactive Online Learning, 9(2), Summer.

Bates, A. (1990). Interactivity as a criterion for media selection in distance education. Annual Conference of the Asian Association of Open Universities. ERIC Document ED329245.

Bonk, C. J., \& Graham, C. R. (2006). The handbook of blended learning environments: Global perspectives, local designs. San Francisco: Jossey-Bass - Pfeiffer.

Castello, V., Guglielman, E., Guspini, M., \& Vettraino, L. (2013). Complex learning frame and evidences. Focus on: Complexity Education, 9(3), September.

D’Angelo, G. (2007). E-authoring-didactic methodologies and models for e-learning content development. Retrieved from: http://www.leonardo-lets.net.

Euroleague for Life Sciences Quality Assurance Support Team \& E-learning Support Team (2012). E-learning: Didactical recommendations and quality assurance an overview. Retrieved from: http:/www.boku.ac.at/fileadmin/data/H05000/ H11000/H11050/H11910/downloads/Publikationen/2012-05-22_ELLS_ELearning_Didactical_Recommendations_and_Quality_Assurance_-_An_ Overview.pdf.

Friesen Norm (August 2012). Report: Defining blended learning. Retrieved from: http://learningspaces.org/papers/Defining_Blended_Learning_NF.pdf.

Garrison, D., \& Vaughan, N. (2008). Blended learning in higher education: Framework, principles, and guidelines. San Francisco: John Wiley \& Sons.

Guglielman, E. (2013). Rethinking e-learning accessibility: Toward didactic guidelines to design inclusive activities. Paper presented at 2013 ATEE Winter Conference, Learning \& teaching with media \& technology, Genoa, 7-9 March. Retrieved from: http://www.guglielman.com/index.php/eleonora-guglielman-download/ articoli-di-eleonora-guglielman.

Heller, R. (2008). A cost benefit analysis of face-to-face and virtual communication: Overcoming the challenges.

InWEnt - Internationale Weiterbildung und Entwicklung gGmbH (2006). Didactic design of e-learning measures: E-learning in vocational education and training. Beiträge aus der Praxis der beruflichen Bildung, 22. Retrieved from: http:// www.giz.de/akademie/de/downloads/giz2013-en-elearning-lehrbrief-22.pdf.

Knowles, M. (1970). The modern practice of adult education.

Littlejohn, A., \& Pegler, C. (2007). Preparing for blended e-learning. Abingdon New York: Routledge.

Moore, M. G., \& Anderson, W. G. (2003). Handbook of distance education. Mahwah, NJ: Lawrence Erlbaum Associates Publishers.

Park, Y., \& Moser, F. Z. (2008). Identifying the role of the International Consortium "MIT/LINC" in supporting the integration of ICT in higher education in 
emerging countries. Journal of Science Education and Technology, 17(2), April, 197-207.

Pritchard, A. (2007). Effective teaching with Internet technologie. London - Thousand Oaks, CA: Paul Chapman - Sage.

Rhode, J. F. (2008). Interaction equivalency in self-paced online learning environments: An exploration of learner preferences. Doctoral dissertation, Capella University. Retrieved from: http://www.jasonrhode.com/publications/dissertation/.

Rhode, J. F. (2009). Interaction equivalency in self-paced online learning environments: An exploration of learner preferences. Interactional Review of Research in Open and Distance Learning, 10(1). Retrieved from: http://www.irrodl. org/index.php/irrodl/article/view/603/1179.

Rowley, D. J., Lujan, H. D., \& Dolence, M. G. (1997). Strategic change in colleges and universities: Planning to survive and prosper. San Francisco: Jossey-Bass.

Sorensen, E., \& Ó Murchú, D. (Eds.). (2006). Enhancing learning through technology. Hershey, PA: Information Science.

Spence, M. (1973). Job market signaling. The Quarterly Journal of Economics, 87(3), 355-374.

UNESCO - Institute for Information Technologies in Education (2013). Engineering of learning: Conceptualizing e-didactics. Retrieved from: http://iite.unesco. org/pics/publications/en/files/3214730.pdf.

Zellweger, F. (2003). E-Learning strategy: Findings from an empirical study of «innovative» higher education institutions. In A. Rossett (Ed.), Proceedings of World Conference on e-learning in corporate, government, healthcare, and higher education (pp. 829-832). Chesapeake, VA: Association for the Advancement of Computing in Education.

Zellweger, F. (2007a). The strategic management of e-learning support. Münster - New York: Waxmann.

Zellweger, F. (2007b). Faculty adoption of educational technology. Educause Quarterly, 1 .

Zemsky, R., \& Massy, W. (2003). Thwarted innovation: What happened to e-learning and why. A learning Alliance report. Retrieved from: http://www.immagic. com/eLibrary/ARCHIVES/GENERAL/UPENN_US/P040600Z.pdf.

\section{RiassunTO}

Questo articolo presenta alcune teorie sul «blended learning», con particolare riferimento alla sua applicazione nella formazione degli adulti e nell'apprendimento permanente. Si sostiene che la buona riuscita delle applicazioni del "blended learning" dipende fortemente 
dal rapporto contesto-soggetto, dagli attori coinvolti (tutor, studenti) e dalla loro capacità di adattarsi in modo tempestivo alle sfide impreviste. Tutto sommato sembra che per sua natura il "blended learning» sia adatto per gli studenti adulti perché la loro decisione di frequentare un corso di formazione è sottoposta ai vincoli del tempo e del costo, mentre, di contro, essi hanno la motivazione personale e l'esperienza necessarie per essere in grado di offrire suggerimenti costruttivi per il miglioramento del corso frequentato.

Parole chiave: Blended learning, Formazione continua degli adulti, Interazione. 